\title{
Navier-Stokes Analysis and Experimental Data Comparison of Compressible Flow in a Diffusing S-Duct
}

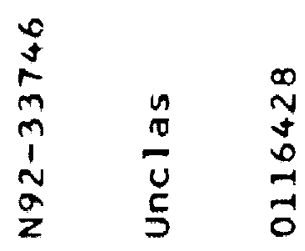

Iowa State University
Ames, Iowa

Gary J. Harloff

Sverdrup Technology, Inc.

Lewis Research Center Group

Brook Park, Ohio

Bruce A. Reichert

National Aeronautics and Spāce Administration

Lewis Research Center

Cleveland, Ohio

and

Steven R. Wellborn

Iowa State University

Ames, Iowa
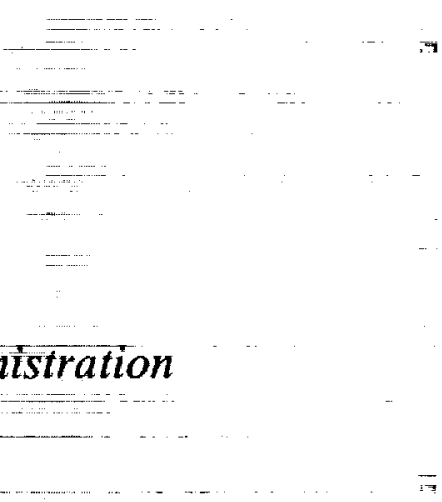

10th Applied Aerodynamics Conference Exhibit

sponsored by the American Institute of Aeronautics and Astronautics

Palo Alto, California, June 22-24, 1992

\section{N/SN}




\author{
Gary J. Harloff ${ }^{*}$ \\ Sverdrup Technology, Inc., LERC Group, Brook Park, Ohio, \\ Bruce A. Reichert ${ }^{\dagger}$ \\ NASA Lewis Research Center, Cleveland, Ohio \\ Steven R. Wellborn ${ }^{\ddagger}$ \\ Iowa State University, Ames, Iowa
}

\begin{abstract}
Full three-dimensional Navier-Stokes computational results are compared with new experimental measurements for the flow field within a round diffusing S-duct. The present study extends previous computational and experimental results for a similar smaller scale S-duct. Predicted results are compared with the experimental static and total pressure fields, and velocity vectors. Additionally, wall pressures, velocity profiles in wall coordinates, and skin friction values are presented. The CFD results employ algebraic and $k-\epsilon$ turbulence models. The CFD computed and experimentally determined separated flow field is carefully examined.
\end{abstract}

\section{Introduction}

M any aircraft employ bending rectangular and circular duct geometries in the inlet and exhaust of the propulsion systems. Examples of aircraft with inlet S-ducts include the Boeing 727, Lockheed Tristar (L1011), General Dynamics F-16, and McDonnell-Douglas F-18. Often, the cross-sectional area of the S-duct increases downstream in order to decelerate the flow and achieve higher static pressure at the engine compressor. To achieve maximum engine performance the $S$-duct should minimize flow ficld total pressure losses throughout the duct and minimize total pressure distortion at the duct exit to avoid engine stall.

Changes in the duct cross-sectional shape or curvature of the ducl centerline give rise to streamline curvature. The cross stream pressure gradients resulting from the streamline curvature can produce significant secondary flows. Additionally, the adverse streamwise pressure gradient caused by increasing cross-sectional area can lead to flow separation. Often, the aircraft designer faces a difficult dilemma. Size and weight restrictions

\footnotetext{
"Senior Staff Scientist, Propulsion Aerodynamics Section, Associate Fellow AIAA

${ }^{\dagger}$ Aerospace Engineer, Inlet, Duct, and Nozzle Flow Physics Branch, Member AIAA.

${ }^{\ddagger}$ Research Assistant, Mechanical Engineering Department, Student Member AIAA.

Copyrighe 1991 by the Americen Institute of Aeronautics and Astronautics, lac. No copyright is esterted in the United States under Tite 17, U.S. Cade. The U.S. Government ban a royalty-fice ticenwe to exereive all rights under the copyright claimed herein for Governmental purpowes. All other rights are reserved by the copyright owner.
}

encourage the use of shorter S-ducts. However, this results in greater streamline curvature and adverse pressure gradients and increases the risk of unacceptable duct performance.

The performance of these types of ducts is usually determined by wind tunnel testing. Researchers at NASA Lewis Research Center are developing computational fluid dynamic (CFD) methods to aid the design and analysis of aircraft propulsion components and systems. A review of this effort is given by Anderson. ${ }^{1} \mathrm{Re}-$ cently, CFD capabilities have improved, and both parabolized and full Navier-Stokes computer programs are used to predict the flows in these ducts. The highly threedimensional and perhaps separated flow in a diffusing $S$-duct presents a substantial challenge to CFD. A careful comparison of numerical predictions with detailed experimental data is necessary to establish and improve the numerical accuracy.

The purpose of the present study is to predict the measured flow ficld with a full Navier-Stokes (FNS) computer program, the PARC3D code, of a representative three-dimensional duct geometry with strong secondary flows. The full, three-dimensional Navier-Stokes equations have bcen solved using algebraic and $k-\epsilon$ turbulence models. CFD computations of the flow through a diffusing S-duct, with concurrent experimental measurements were performed at NASA Lewis Research Center. This concurrent approach allows a synergism that is beneficial to both efforts and proved to be particularly successful in the recently completed study of circular-torectangular transition duct flows. ${ }^{2}$

The computational and experimental work was undertaken to extend previous studies, to provide for additional CFD validation data and to help model flows with strong secondary flows and boundary layer separation. Previous experimental studies in the incompressible range have been considerable. ${ }^{3-8}$ Vortex pairs are evident in the exit planes of S-ducts, transition ducts, and bending rectangular ducts. These vortices are due to secondary flows induced by pressure gradients. However, although benchmark CFD validation data exist for incompressible flow, few data sets are available for compressible CFD validation.

Previous incompressible and compressible flow numerical predictions have been extensive. ${ }^{9-15}$ A possible limitation of both algebraic and $k-\epsilon$ turbulence modeling for strong secondary flows has been noted by several researchers. The mechanism that produces the low total 
pressure region at the exit is an inviscid rotational phenomenon, provided an inlet boundary layer is present. Thus, correct inlet boundary conditions are obviously needed. Previous computational investigations appear to be limited to FNS or PNS computations that do not account for the upstream effect of mass flow adjustment, boundary layer growth, and flow blockage; i.e., the published solutions have specified inlet conditions, with the exception of Ref. 15. In this present study, the upstream static conditions were allowed to adjust.

This study extends the computational study of Harloff et al. ${ }^{16,17}$ and Smith et al. ${ }^{18}$ In the previous studies the computed total pressures were generally in good agreement with the experimental data of Vakili et al. ${ }^{19}$, and the velocity vectors were in qualitative agreement with the experimental data. The predicted static pressures did not compare as well with the measurements, possibly due to a failure of the turbulence model to properly account for secondary flow and imbedded vorticity effects, or possibly to undocumented disturbances in the inflow or inadequate grid resolution. However, the two counter-rotating vortices at the S-duct exit were predicted. It was concluded that the modeling could be improved by incorporating a finer grid and more advanced turbulence models. The first grid point in the sublayer had a $y^{+}$of about 14. The complete duct length should be modeled because of the importance of vorticity generation effects. Additional fundamental experimental and numerical studies were recommended to properly address the turbulence modeling issues with imbedded vortices and strong secondary flows. The present study is conducted with a much finer grid with the first points off the duct surface having a $y^{+}$value of order 1 . The total number of grid

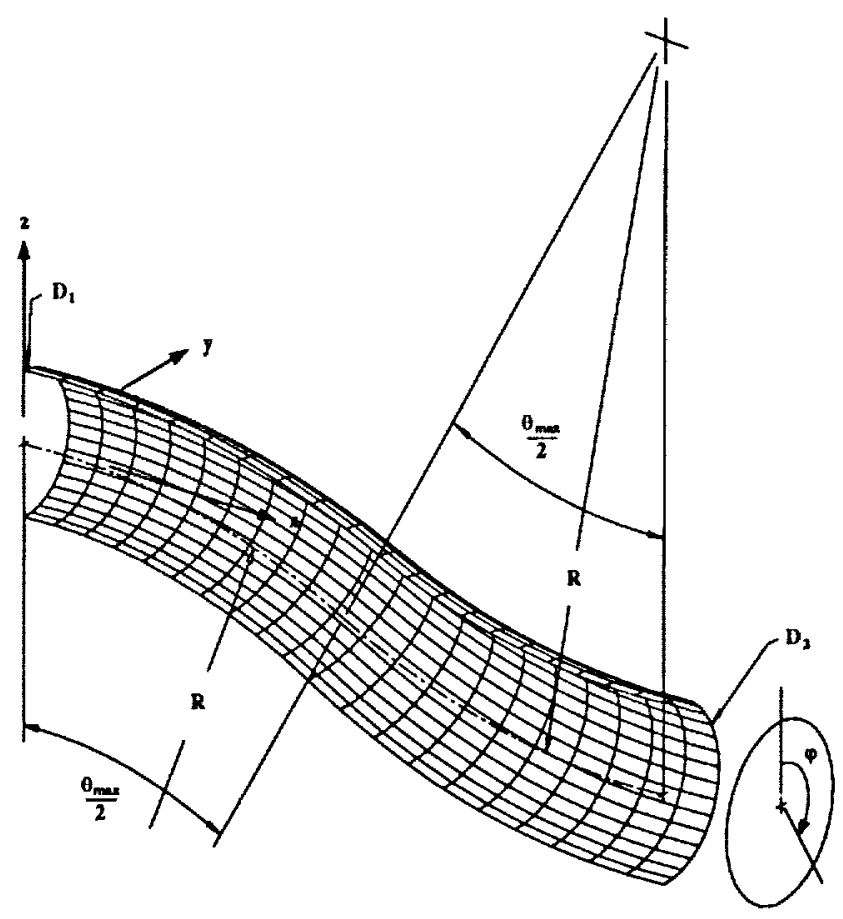

Fig. 1 The geometry of the diffusing S-duct points for the present study is 500,479 compared to the previous number of 82,810 .

\section{Experimental and Numerical Methods}

The geometry of the diffusing S-duct examined in this study is shown in Fig. 1. The duct centerline is defined by two circular arcs with an identical radius of curvature, $R$, and subtended angle $\theta_{\max } / 2$. For the duct constructed, $R=40.2$ inches and $\theta_{\max } / 2=30^{\circ}$. Both arcs lie within the $x z$-plane as shown in Fig. 1 . The coordinates $\left(x_{c l}, y_{c l}, z_{c l}\right)$ of the duct centerline are given by Eq. (1). The cross-sectional shape of the duct perpendicular to the centerline is circular. The radius of the cross section varies with the arc angle $\theta$ and is given by Eq. (2). In Eq. (2) $r_{1}$ is the radius at the duct inlet and $r_{2}$ is the radius at the duct exit (with corresponding inlet and exit diameters $D_{1}$ and $D_{2}$ ). The values used for construction are $r_{1}=4.02$ inches and $r_{2}=4.95$ inches which provide an area ratio of $A_{2} / A_{1}=1.52$. The offset of the duct resulting from centerline curvature is $1.34 D_{1}$, and the length of the duct measured along the centerline is $5.23 D_{1}$. This duct is larger than, but geometrically similar to, the duct studied by Vakili et al. ${ }^{19}$

$$
\begin{aligned}
& \text { For } 0 \leq \theta \leq \frac{\theta_{\max }}{2} \\
& x_{c l}=R \sin \theta \\
& y_{c l}=0 \\
& z_{c l}=R \cos \theta-R \\
& \text { For } \frac{\theta_{\max }}{2} \leq \theta \leq \theta_{\max } \\
& x_{c l}=2 R \sin \left(\frac{\theta_{\max }}{2}\right)-2 R \sin \left(\theta_{\max }-\theta\right) \\
& y_{c l}=0 \\
& z_{c l}=2 R \cos \left(\frac{\theta_{\max }}{2}\right)-R-R \cos \left(\theta_{\max }-\theta\right) \\
& \frac{r}{r_{1}}=1+3\left(\frac{r_{2}}{r_{1}}-1\right)\left(\frac{\theta}{\theta_{\max }}\right)^{2}-2\left(\frac{r_{2}}{r_{1}}-1\right)\left(\frac{\theta}{\theta_{\max }}\right)^{3}
\end{aligned}
$$

While discussing numerical and experimental results, axial position will refer to distance to cross stream planes measured along the duct centerline and normalized by the duct inlet diameter, $s / D_{1}$. Position within cross stream planes is specified by the polar angle $\phi$, measured from the vertical in a positive clockwise direction as shown in Fig. 1, and the radial distance from the centerline $r$.

\section{Experiment}

Experimental measurements of the duct flow ficld were made at NASA Lewis Research Center using the 
Internal Fluid Mechanics Facility. This facility was designed to support the research of a variety of internal flow configurations and is described in detail by Porro et al. ${ }^{20}$ Smooth circular pipes of appropriate diameter were attached upstream and downstream of the S-duct to provide a uniform incoming flow and a smooth, continuous condition for flow exiting the duct. The lengths of the upstream and downstream pipes were each $3.75 D_{1}$. Detailed measurements were made with calibrated three- and five-hole probes at cross-stream planes near the duct's inlet (at $s / D_{1}=-0.5$, one-half inlet diameter upstream of the $S$-duct inlet) and exit (at $s / D_{1}=5.73$, one-half inlet diameter downstream of the S-duct exit). The surface static pressure was measured through 220 static pressure taps located axially at angles $\phi=10^{\circ}, 90^{\circ}$, and $170^{\circ}$ and circumferentially within cross stream planes at $s / D_{1}=$ $0.96,2.97$, and 4.01 . The duct inlet Mach number was $M=0.6$ for all experimental measurements. The inlet boundary layer thickness was approximately $4 \%$ of the duct inlet diameter and the Reynolds number, based on inlet diameter was approximately $R e_{D_{1}}=2.6 \times 10^{6}$. Additional information about the experimental program is contained in Ref. 21 .

\section{Computation}

The PARC3D 22 computer program solves the full, three-dimensional Reynolds-averaged Navicr-Stokes equations in strong conservation form with the Beam and Warming approximate factorization algorithm. The implicit scheme uses central differencing for a curvilinear set of coordinates. The code was originally developed as AIR3D by Pulliam and Steger; ${ }^{23}$ Pulliam later added the Jameson ${ }^{24}$ artificial dissipation and called the code ARC3D ${ }^{25}$ Cooper adapied the ARC3D code for internal propulsion application and named the code PARC3D. The computations were carried out on the NASA Lewis YMP computer.

The Baldwin-Lomax ${ }^{26}$ algebraic turbulence model, developed for two-dimensional flow, assumes isotropic equilibrium turbulence and has no allowance for secondary flow effects. The computer code uses only vorticity in the local boundary layer to avoid secondary flow effects on the eddy viscosity. The length scale search was restricted to be within the wall boundary layer. A low Reynolds number $k-\epsilon$ turbulence model of Speziale et $a l .{ }^{27}$ was also used. The numerical solution algorithm is that of Nichols. ${ }^{28}$

The grid was developed using trigonometric relations for the walls and centerline from Eqs. (1) and (2). The computer program Gridgen was used to build the grid from the definition of the walls and centerline. Three blocks were used with $\mathrm{O}$ grid distribution of $32 \times 71 \times$ $53,69 \times 71 \times 53$, and $32 \times 71 \times 53$ in axial, circumferential and radial directions respectively. A fourth block with an $\mathrm{H}$ grid was used in the center with distributions of $129 \times 11 \times 15$. The largest grid models the S-duct, the other two grids model the circular pipes located upstream and downstream of the S-duch, as described in the previous section. The first point off the duct surface has a $y^{+}$value of less than 1 .

The boundary conditions used were no slip at the walls, total pressure and temperature specified at the entry of the circular pipe upstream of the S-duct, static pressure specified at the exit of the circular pipe downstream of the $S$-duct, and symmetry about the $x z$-plane. The entrance velocity and static pressure were solved by averaging an incoming and an extrapolated interior Riemann invariant.

\section{Results and Discussion}

The total and static pressures in this section are presented as pressure coefficients given by Eqs. (3) and (4). The pressures $p_{0}$ and $p$ represent the local values of total and static pressure. The reference variables, subscripted cl (centerline) or wall, were evaluated at a location one radius upstream of the $S$-duct inlet $\left(s / D_{1}=\right.$ $-0.5)$.

$$
\begin{aligned}
C_{p_{0}} & =\frac{p_{0}-p_{\text {wall }}}{p_{0, \mathrm{cl}}-p_{\text {wall }}} \\
C_{p} & =\frac{p-p_{\text {wall }}}{p_{0, \mathrm{cl}}-p_{\text {wall }}}
\end{aligned}
$$

Plots of velocity presented in wall coordinates have been normalized by the conventional definitions, Eq. (5) where $\rho, \nu$, and $\tau_{w}$ represent density, kinematic viscosity, and wall shear stress.

$$
u^{+}=\frac{u}{u^{*}}, y^{+}=\frac{u^{*} y}{\nu}, u^{*}=\sqrt{\frac{\tau_{w}}{\rho}}
$$

Skin friction results are presented as a local skin friction coefficient, defined by Eq. (6)

$$
C_{f}=\frac{\tau_{w}}{\frac{1}{2} \rho_{c l} U_{c l}^{2}}
$$

The computed upstream total pressure coefficient contours (at $s / D_{1}=-0.5$ ), as shown in Fig. 2, agrce well with the experimental measurements. Fig. 3 shows the velocity profile in wall coordinates. Experimental values have been plotted with symbols and numerical results with lines. Calculations for both the $k-\epsilon$ and algebraic turbulence models agree well with the experimental data. Both experimental and numerical results show negligible circumferential variation, indicating minimal upstream influence of the $S$-duct at this location. The algebraic model results indicate a slight velocity increase at $\phi=10^{\circ}$. The two predictions and the experimental data indicate that the entrance velocity profile was a fully developed turbulent boundary layer profile.

Values of the computed (lines) and experimental (symbols) surface static pressure coefficient at $\phi=$ $10^{\circ}, 90^{\circ}$, and $170^{\circ}$ are shown in Fig. 4 for both turbulence models. The shaded region from $2.02 \leq s / D_{1} \leq$ 


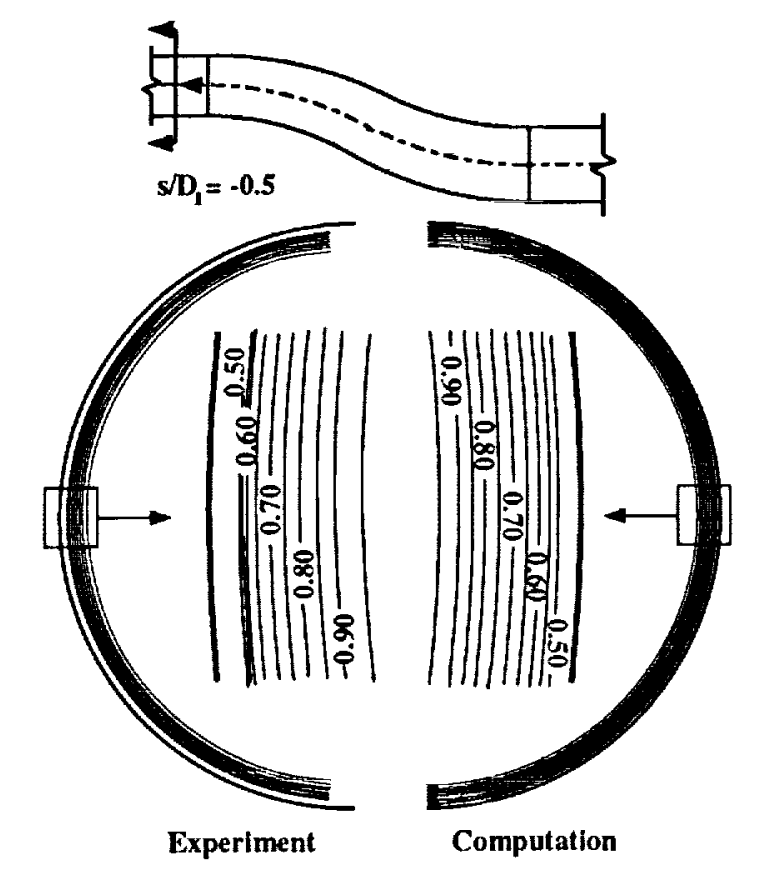

(a)

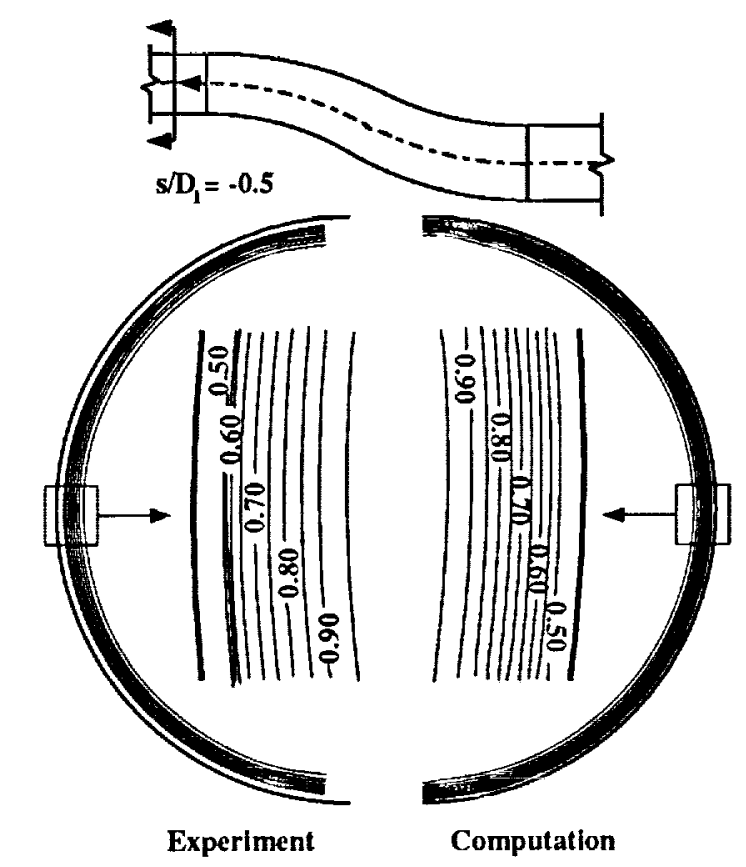

(b)

Fig. 2 Total pressure coefficient contours at $s / D_{1}=-0.5$, (a) $k-\epsilon$ turbulence model, (b) algebraic turbulence model.

4.13 in Fig. 4 indicates the location of separation at $\phi=180^{\circ}$ as determined by experimental surface flow visualization. The $k-\epsilon$ and the algebraic turbulence models predict separation between $2.59 \leq s / D_{1} \leq 4.25$ and $2.69 \leq s / D_{1} \leq 4.52$, respectively. For computational results, separation was determined by examining the velocity at the first grid point off the duct surface along $\phi=180^{\circ}$. Note that the predicted separation lengths

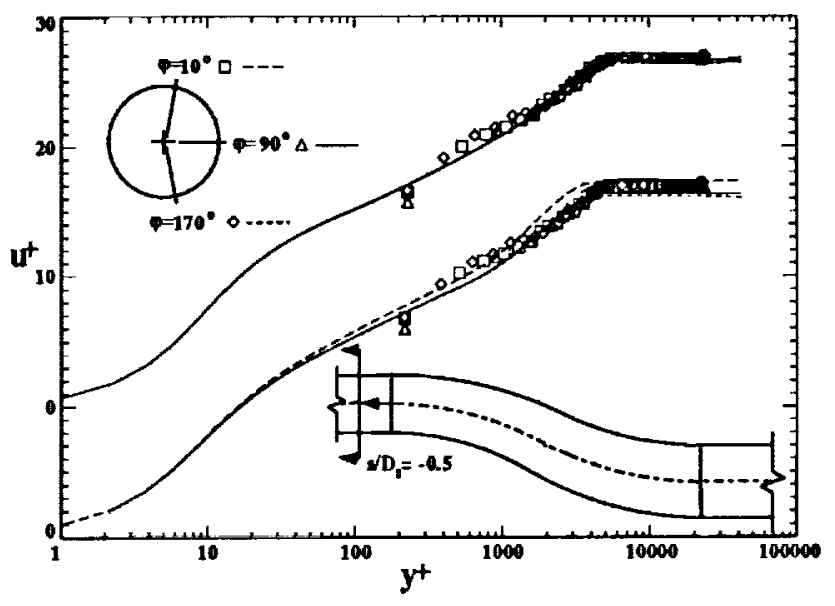

Fig. 3 Boundary layer wall coordinate plots at $s / D_{1}=-0.5, k-\epsilon$ turbulence model (upper), algebraic turbulence model (lower).

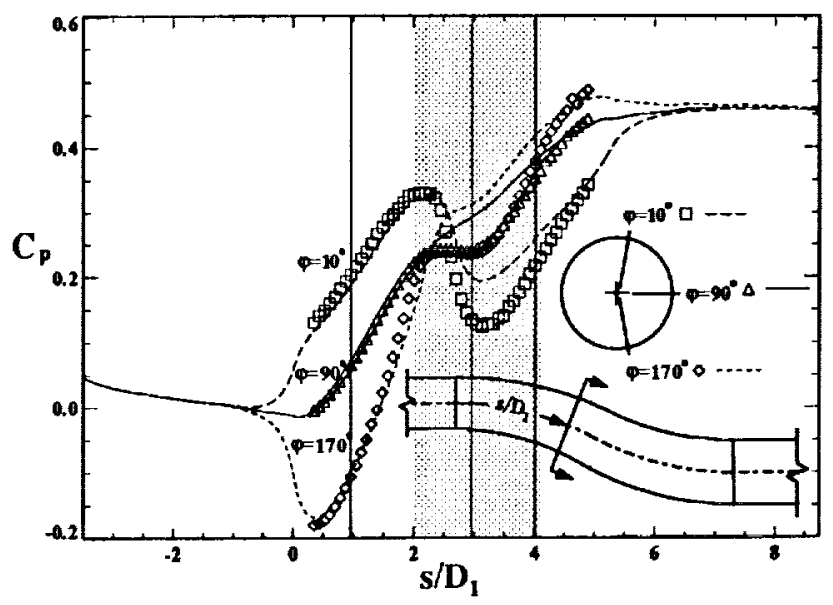

(a)

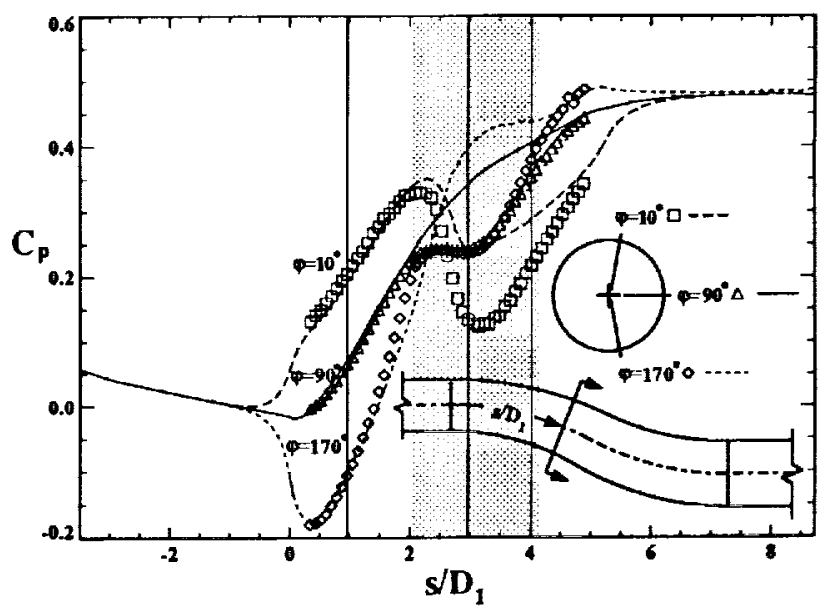

(b)

Fig. 4 Axial surface static pressure coefficient, (a) $k-\epsilon$ turbulence model, (b) algebraic turbulence model.

of 1.66 ( $k-\epsilon$ model) and 1.83 (algebraic model) are shorter than the experimental value of 2.11 . The com- 


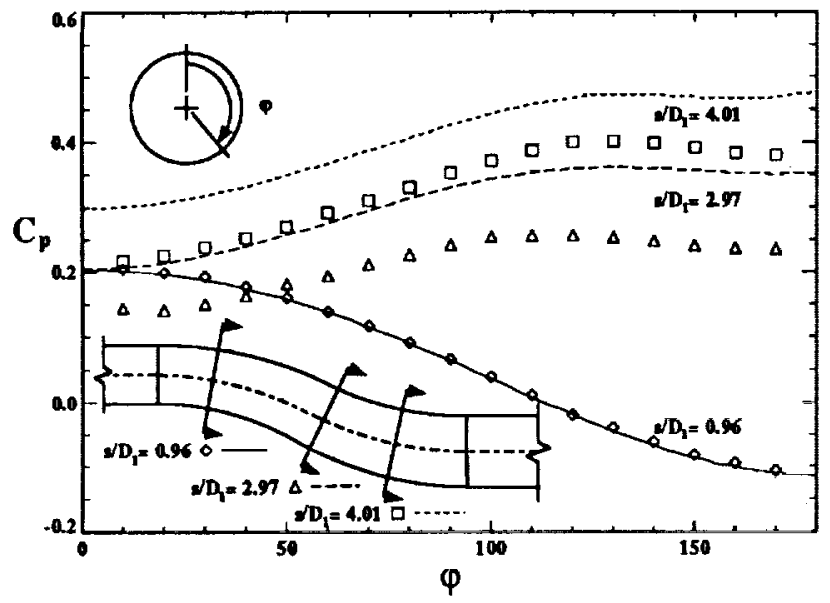

(a)

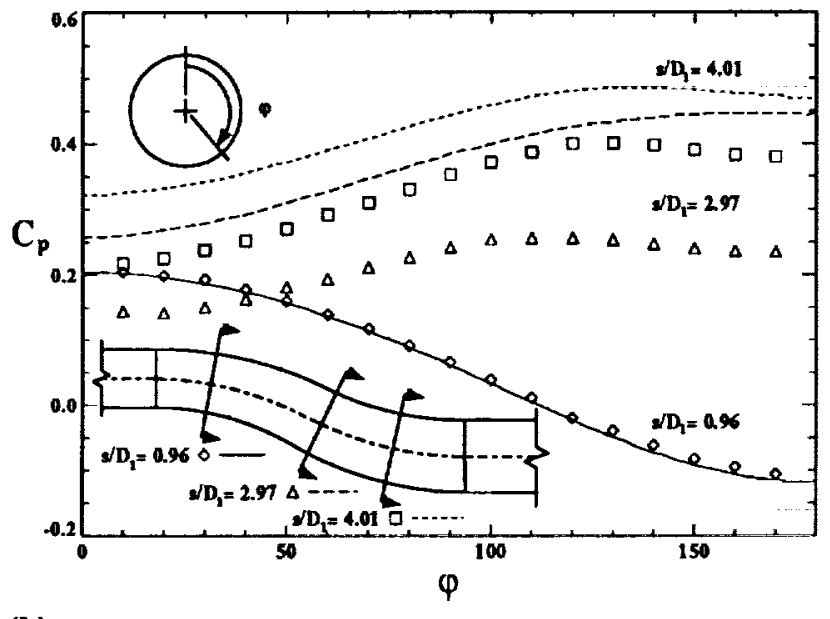

(b)

Fig. 5 Circumferential surface static pressure coefficient, (a)k $-\epsilon$ turbulence model, (b) algebraic turbulence model.

puted pressures upstream of the experimental separation region are in good agreement with each other and with the experimental data. The flow deceleration that results from increasing duct cross sectional area and duct surface curvature stops at $\phi=90^{\circ}$ and $170^{\circ}$ in the region $2 \leq s / D_{1} \leq 3$ because of aerodynamic flow blockage. The flow blockage results from the boundary layer separation. Low momentum fluid is convected away from the duct surface by secondary flow. The $k-\epsilon$ model follows the experimental data in the separation region more closely than the algebraic model. Both turbulence models predict higher values of static pressure than was observed experimentally. The constant value of static pressure at both $\phi=90^{\circ}$ and $170^{\circ}$ in the region $2 \leq s / D_{1} \leq 3$, is not predicted by either turbulence model. However, at $\phi=170^{\circ}$ the $k-\epsilon$ turbulence model predicts a constant surface static pressure at $s / D_{1}=2.5$ and the algebraic model predicts a similar result at $s / D_{1}=3.2$. Thus the angular extent of the boundary layer separation is under predicted, and the predicted separation occurs further downstream than was observed experimentally. This

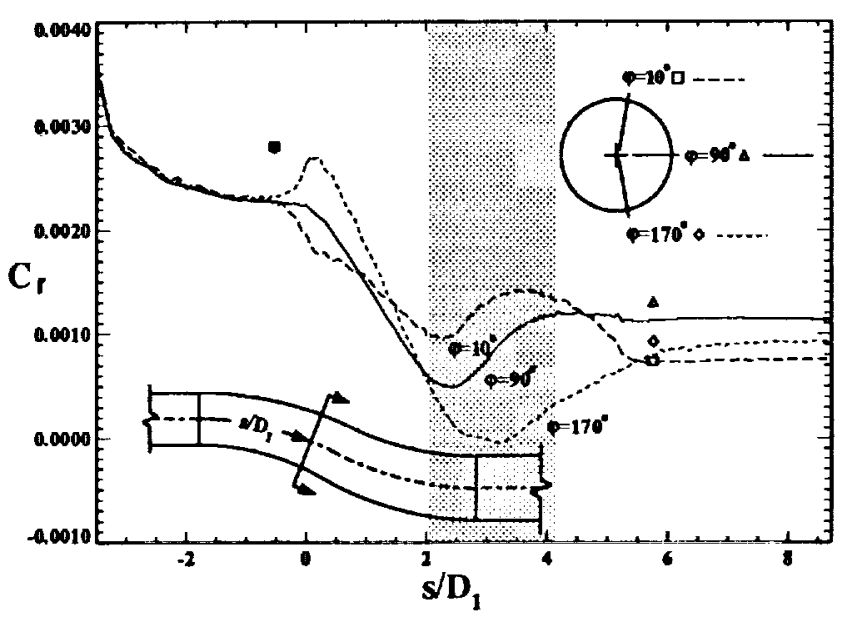

(a)

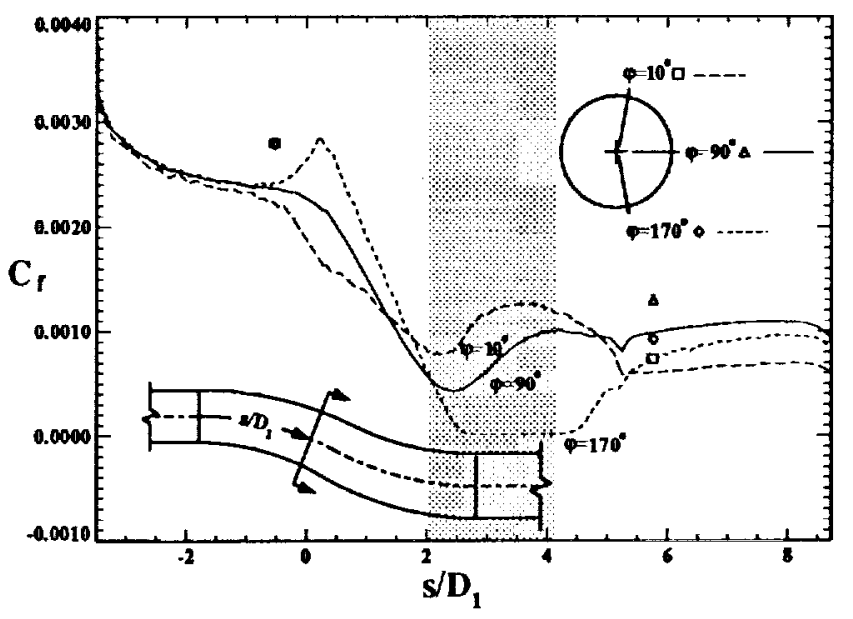

(b)

Fig. 6 Skin friction coefficient, (a) $k-\epsilon$ turbulence model, (b) algebraic turbulence model.

indicates that the turbulence models do not correculy account for boundary layer separation and/or strong three dimensional flow effects. Both turbulence models approach the experimental data downstream of the separation.

The three vertical lines in Fig. 4 at $s / D_{1}=0.96$, 2.97 , and 4.01 indicate the location of the circumferential surface static pressure measurements shown in Fig. 5. Good agreement in the computations for both turbulence models is observed at $s / D_{1}=0.96$, upstream of the boundary layer flow separation. Both computations of surface static pressure at $s / D_{1}=2.97$ and 4.01 are higher than the experimental data. The $k-\epsilon$ model predictions are closer to the experimental data and the results for both turbulence models are similar in shape to the experimental data. The higher values of computed static pressure at $s / D_{1}=2.97$ and 4.01 indicate that the blockage resulting from the boundary layer separation, as previously mentioned, is under predicted by both turbulence models.

Values of the computed skin friction coefficient at $\phi=10^{\circ}, 90^{\circ}$, and $170^{\circ}$ are shown in Fig. 6. At 


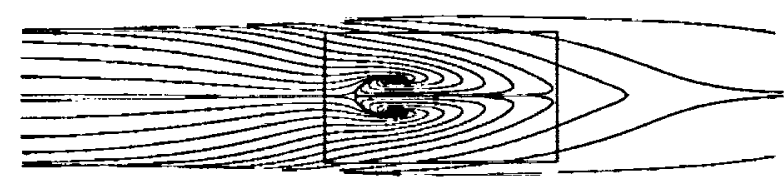

(a)

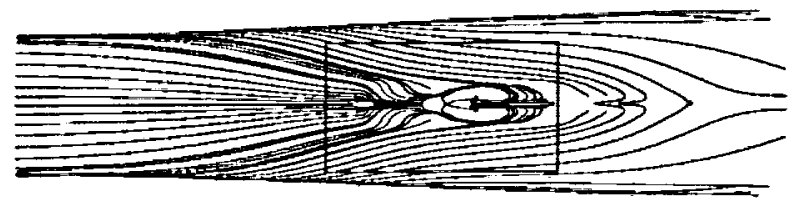

(b)

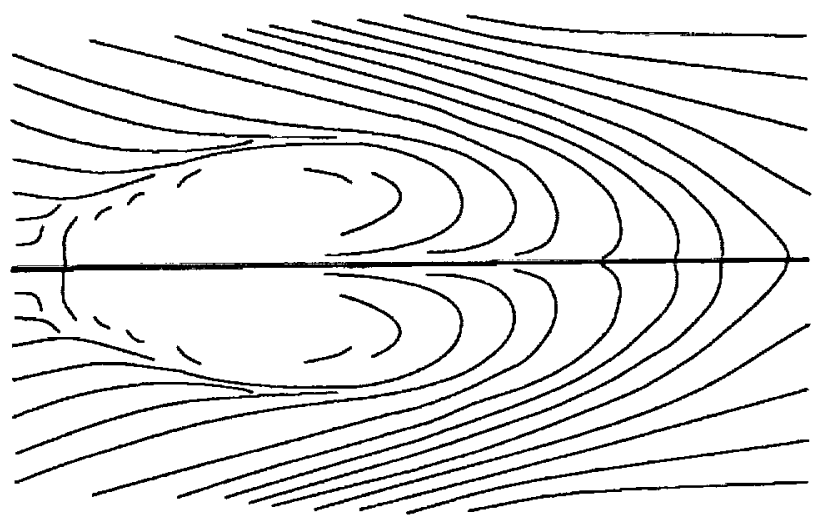

(c)

Fig. 7 Streamlines near the S-duct surface, (a) $k-\epsilon$ turbulence model, (b) algebraic turbulence model, (c) experimental result.

$s / D_{1}<-0.5$ the skin friction is independent of $\phi$ for the $k-\epsilon$ model and is lower at $\phi=10^{\circ}$ than either $90^{\circ}$ or $170^{\circ}$ for the algebraic model. Upon entering the duct the skin friction first increases at $\phi=170^{\circ}$ as the flow accelerates and decreases at $\phi=10^{\circ}$ as the flow decelerates. Skin friction decreases at $s / D_{1}>0.3$ as the whole flow decelerates. The values predicted by both turbulence models are similar both up and downstream of the separation. The zero skin friction region is longer in the algebraic case than the $k-\epsilon$ case. The skin friction coefficients are expected to be negative in separated flow. The numerical models prevent the $C_{f}$ values from becoming very negative. Experimental data, available at only two axial locations, show values of skin friction higher than was predicted.

The computed streamlines near the wall for both turbulence models are compared with the experimental surface flow visualization in Fig. 7. The flow in Fig. 7 is from left to right and the view is looking in the vertical $z$-axis direction (or the projection onto the horizontal $x y$-plane). The experimental results show only the boxed region indicated in Fig. 7 (a) and (b). The similar features include large flow angles (relative to the $x$-axis) and the region of separation indicated by the pair of spiral nodes. The results predicted by the $k-\epsilon$ turbulence model appear to agrce better with the experimental results than the algebraic turbulence model.

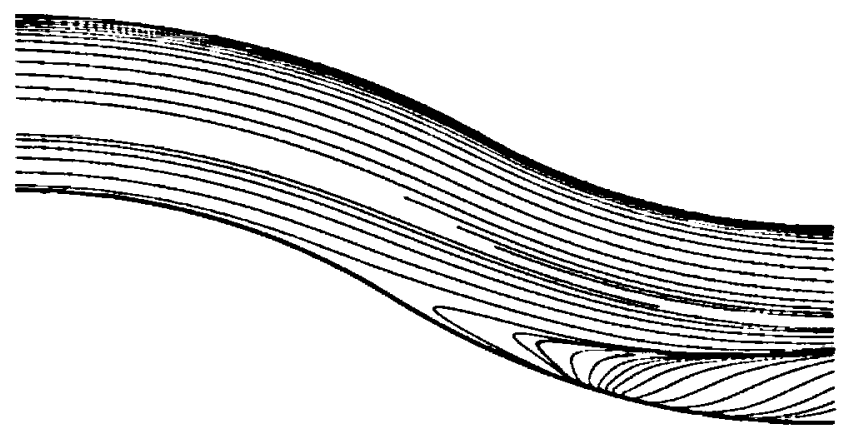

(a)

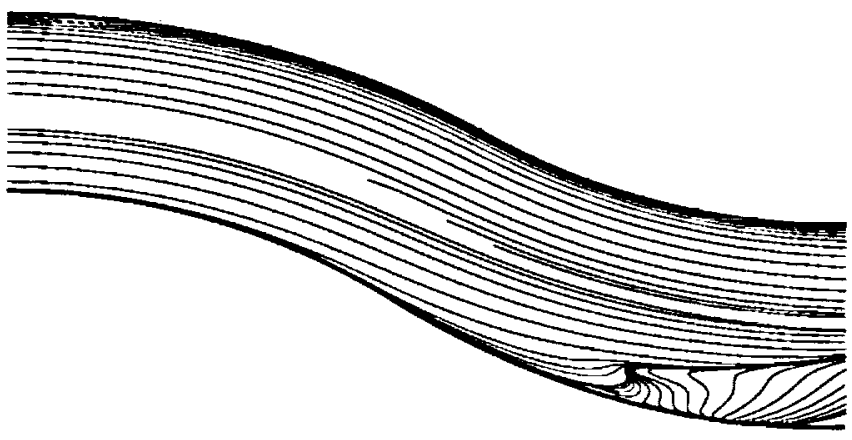

(b)

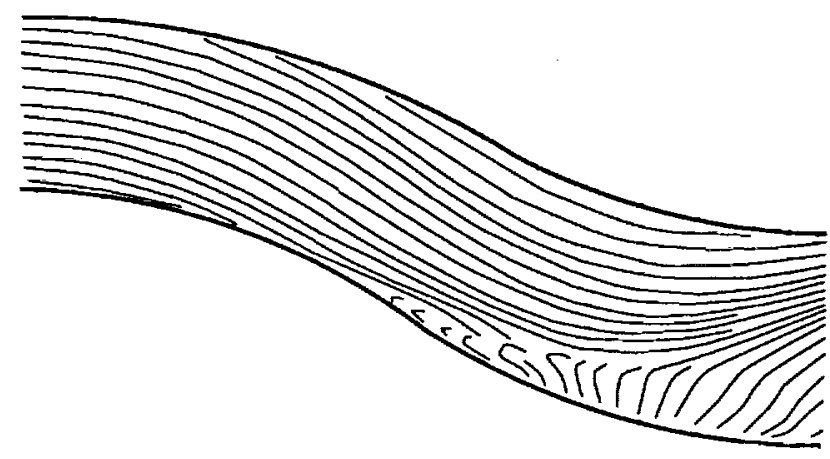

(c)

Fig. 8 Streamlines along the S-duct centerline, (a) $k-\epsilon$ turbulence model, (b) algebraic turbulence model, (c) experimental result.

The predicted streamlines along the duct centerline are shown in Fig. 8. The experimental result was obtained by placing a thin metal plate between the two symmetric halves of the S-duct, spanning the duct in the $x z$-plane. Symmetry requires the $x z$-plane of the flow field to be a stream surface, therefore not allowing flow across this plane. However, the physical presence of the plate within the S-duct does introduce shear and blockage, so the comparison shown in Fig. 8 should be considered qualitative. The streamlines predicted by the $k-\epsilon$ turbulence model appear more like the experimental data, particularly in the separated region. Following reattachment, both turbulence models predict the flow field region strongly influenced by the separation to lie below the $S$-duct centerline while the experimental results indicate this region extends above the duct centerline. This feature is related to the late CFD separation and 


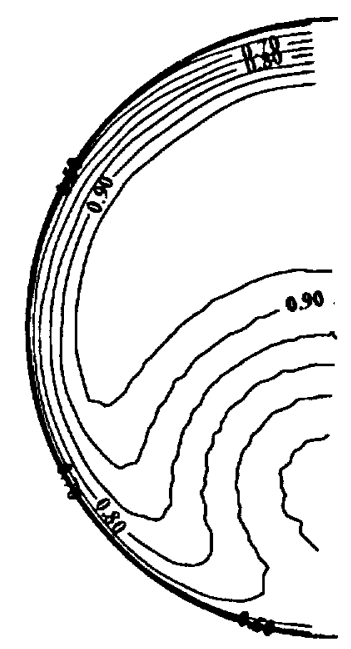

Experiment

(a)

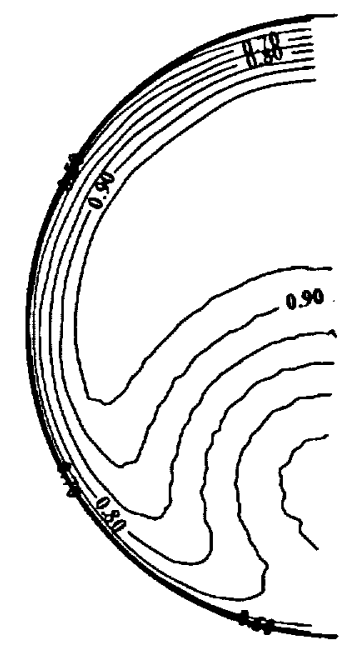

Experiment

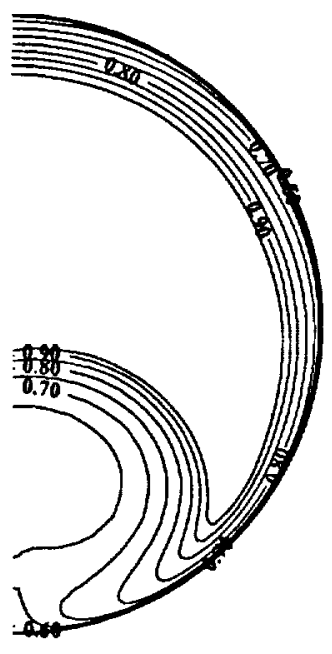

Computation

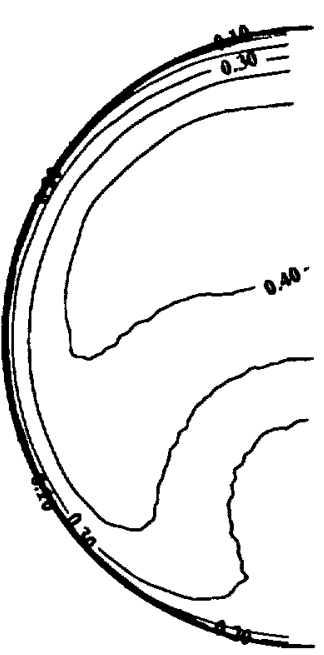

Experiment

(a)

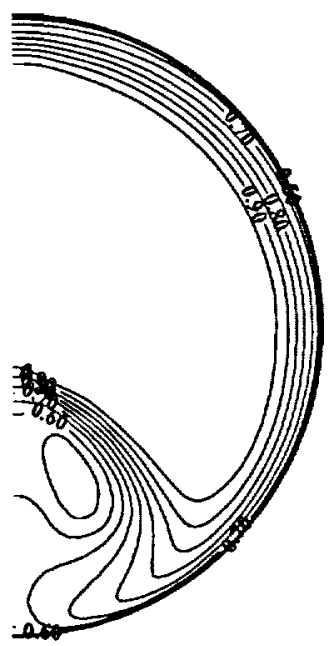

Computation

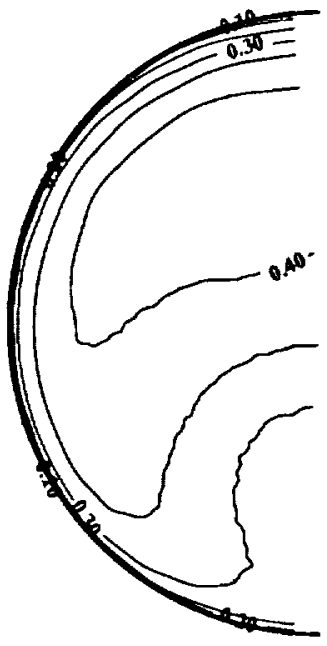

Experiment

(b)

Fig. 9 Total pressure coefficient contours at $s / D_{1}=5.73$, (a) $k-\epsilon$ turbulence model, (b) algebraic turbulence model.

an under prediction of the separation length and lateral extent. The size of the separation, and the aerodynamic blockage, is under predicted by both models.

Contours of the total pressure coefficient at the downstream location (at $s / D_{1}=5.73$, one-half inlet diameter downstream of the S-duct exit) are shown in Fig. 9. The experimentally determined region of diminished total pressure extends above the duct centerline and occupies more area than is predicted by both turbulence models. The predicted values of total pressure are lower in this region then the experimental values. This geometrical difference is undoubledly related to the late separation prediction and the under prediction of the separation size. The predicted pair of counter-rotating vortices is too concentrated compared to the experimental vortices. The shapes of the predicted vortices differ and the $k-\epsilon$ vortices are rounder. The $k-\epsilon$ model predicts a thin-

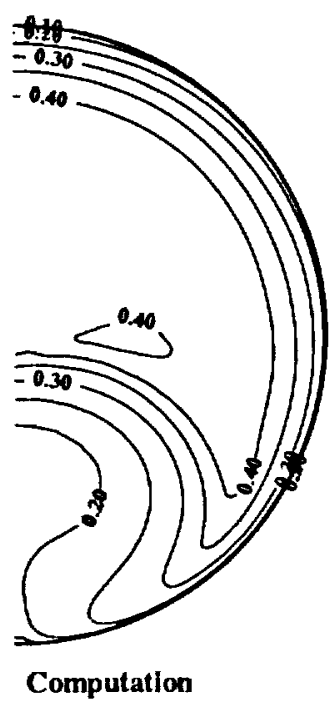

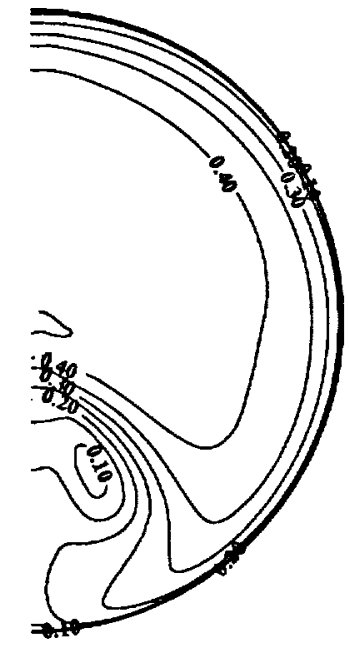

Computation (b)

Fig. 10 Axial Mach number contours at $s / D_{1}=5.73$ (a) $k-\epsilon$ turbulence model, (b) algebraic turbulence model.

ner boundary layer near the vortices than the algebraic model or the experimental data. The axial Mach number contours shown in Fig. 10 are similar except that the 0.4 contour from the experiment is above the duct centerline and above both predicted 0.4 contours. The transverse components of velocity, shown in Fig. 11, are similar to the experimental values. However, the center of the vortices predicted by the $k-\epsilon$ turbulence model are lower and further from the symmetry plane than the algebraic turbulence model predicts. Both turbulence models predict transverse velocities in the region of the vortices that are greater than was observed experimentally, and transverse velocities in the core flow region that are less than was observed experimentally. Because the calculations under predict transverse velocities in the core flow re- 


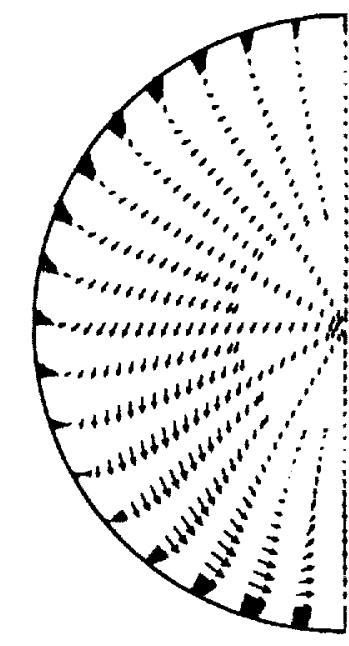

Experiment

(a)

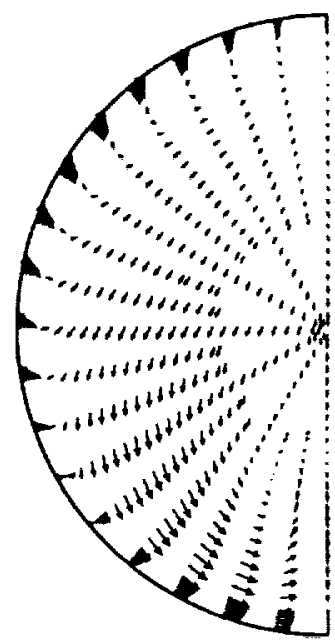

Experiment

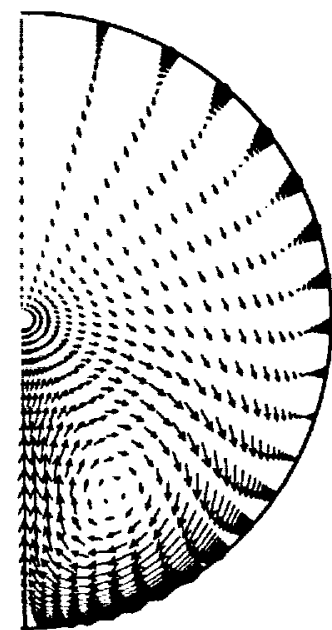

Computation

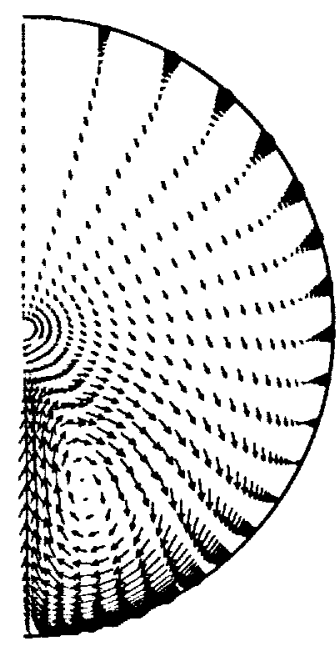

Computation (b)

Fig. 11 Transverse velocity components at $s / D_{1}=5.73$ (a) $k-\epsilon$ turbulence model, (b) algebraic turbulence model.

gion, the predicted vortices are not convected as far from the duct surface as was observed experimentally.

The velocity profiles in wall coordinates are shown in Fig. 12 at the downstream measurement plane. The experimental data and the numerical predictions are in reasonable agreement in the $\log$ linear portion and in qualitatively agreement in the wake region. The $k-\epsilon$ turbulence model predicts $u^{+}$values in the log linear region that are lower than both the numerical results and the results predicted by the algebraic turbulence model. The velocities at $\phi=10^{\circ}$ are higher than the velocities at $\phi=170^{\circ}$ which lie within the region of diminished total pressure. This large departure from the law of the wall has been noted by Schubauer and Klebanof ${ }^{29}$, and Baldwin-Lomax. ${ }^{26}$ and is characteristic of the convected vortices.

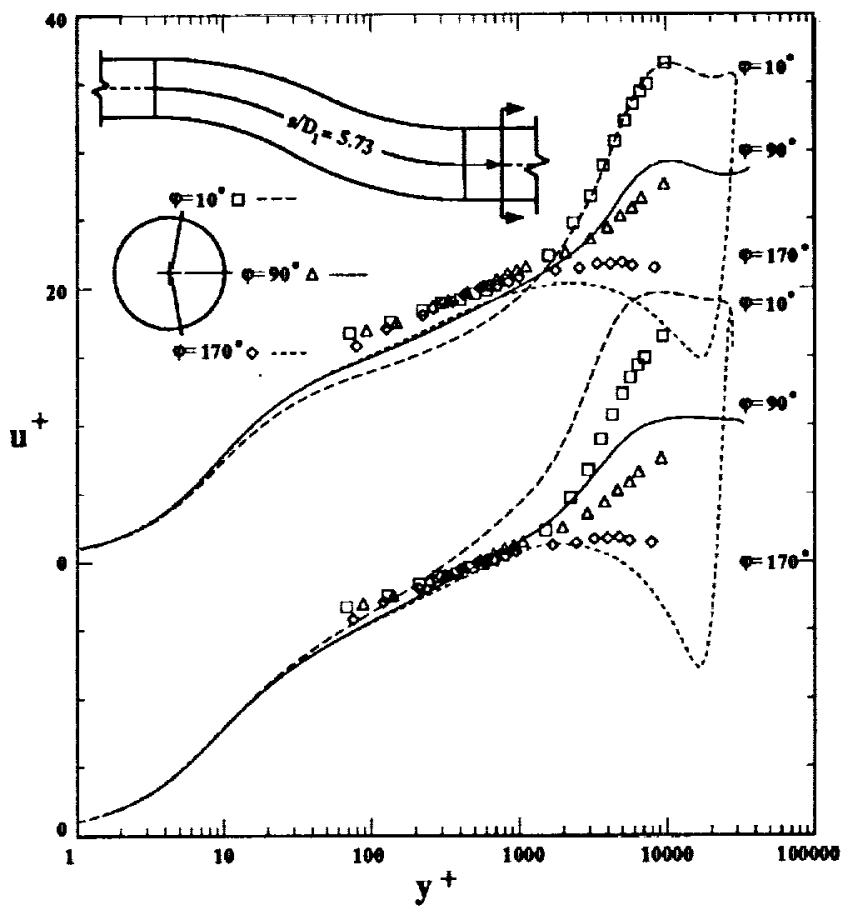

Fig. 12 Boundary layer wall coordinate plots at $s / D_{1}=5.73, k-\epsilon$ turbulence model (upper), algebraic turbulence model (lower).

\section{Conclusion}

The previous CFD studies of compressible, diffusing S-duct flow ${ }^{17,18}$ indicated an inadequacy in either the grid resolution or the algebraic turbulence model used. This work extends the previous studies by utilizing a finer grid and the addition of a $k-\epsilon$ turbulence model. New calculations were completed and compared with a new set of comprehensive experimental data. The computed flow fields are in reasonable agreement with the experimental flow field. Both turbulence models under predict the length and angular extent of the boundary layer separation, and the predicted separation occurs further downstream than was observed experimentally by approximately $0.5 s / D_{1}$. Both turbulence models predict transverse velocities in the region of the counter-rotating vortices that are greater than was observed experimentally, and transverse velocities in the core flow region that are less than was observed experimentally. It is concluded that neither turbulence model adequately accounts for strong secondary flows with separation.

\section{Acknowledgment}

Dr. Bruce Wendt provided valuable assistance in the experimental investigation. The CFD effort of this work was prepared for NASA Lewis Research Center under Contract NAS3-25266, project monitor R. Coltrin. The interior grid was generated with the assistance of J. Bruns. C. F. Smith and J. R. Sirbaugh provided valuable CFD discussions and assistance. 


\section{References}

${ }^{1}$ Anderson, B. H., "Three-Dimensional Viscous Design Methodology of Supersonic Inlet Systems for Advanced Technology Aircraft," Numerical Methods for EngineAirframe Integration, edited by S. N. B. Murthy and G. C. Paynter, AIAA, 1986, pp. 431-480.

${ }^{2}$ Sirbaugh, J. R. and Reichert, B. A., "Computation of a Circular-to-Rectangular Transition Duct Flow Field," AIAA Paper 91-1741, 1991.

${ }^{3}$ Bansod, P. and Bradshaw, P., "The Flow in S-shaped Ducts," Aeronautical Quarterly, Vol. 23, May 1972, pp. 131-140.

${ }^{4}$ Willmer, A. C., Brown, T. W., and Goldsmith, E. L., "Effects of Intake Geometry on Circular Pitot Intake Performance at Zero and flow Forward Speeds," AGARD Tech. Rep. CP-301, 1981.

${ }^{5}$ Guo, R. W. and Seddon, J., "The Investigations of Swirl in an S-duct," Aeronautical Quarterly, Vol. 33, May 1982, pp. 25-58.

${ }^{6}$ McMillan, O. J., "Mean-Flow Measurements of the Flow Field in a Diffusing Bend," NASA CR 3634, 1982.

${ }^{7}$ Taylor, A. M. K. P., Whitelaw, J. H., and Yianneskis, M., "Developing Flow in S-Shaped Ducts II - Circular Cross-Section Duct," Imperial College of Science and Technology NASA Contractor Report 3759, Feb. 1984.

${ }^{8}$ Schmidt, M. C., Whitelaw, J. H., and Yianneskis, M., "Flow in Out-of-Plane Double S-Bends," Imperial College of Science and Technology Tech. Rep. FS/86/30, June 1986.

${ }^{9}$ Rowe, M., "Measurements and Computations of Flow in a Pipe Bend," Journal of Fluid Mechanics, Vol. 43, 1970, pp. 771-783.

${ }^{10}$ Towne, C. E. and Anderson, B. H., "Numerical Simulation of Flows in Curved Diffusers with Cross-Sectional Transitioning Using a Three-Dimensional Viscous Analysis," AIAA paper, 1981. (also NASA TM 81672).

${ }^{11}$ Vakili, A., Wu, J. M., Hingst, W. R., and Towne, C. E., "Comparison of Experimental and Computational Compressible Flow in a S-Duct," AIAA Paper 84-0033, 1984.

${ }^{12}$ Maleckl, R. E. and Lord, W. K., "Parabolized NavierStokes Analysis of Circular-to-Rectangular Transition Duct Flows," SAE Paper 881480, 1988.

${ }^{13}$ Cosner, R. R., "Transonic Propulsion System Integration Analysis at McDonnell Aircraft Corperation," NASA CP 3020, 1988.

${ }^{14}$ Monson, D. J., Seegmiller, H. L., and McConnaughey, P. K., "Comparison of LDV Measurements and NavierStokes Solutions in a Two-Dimensional 180-deg TurnAround Duct," AIAA Paper 89-0275, 1989.
${ }^{15}$ Jenkins, R. C. and Loeffler, A. L., "Modeling of Subsonic Flow Through a Compact Offset Diffuser," AIAA Journal, Vol. 29, Mar. 1991, pp. 287-293.

${ }^{16}$ Harloff, G. J., DeBonis, J. R., Smith, C. F., and Bruns, J. E., "Three-Dimensional Turbulent Computations for a Nondiffusing S-Duct," NASA CR 4391, 1991.

${ }^{17}$ Harloff, G. J., Smith, C. F., Bruns, J. E., and DeBonis, J. R., "Navier-Stokes Analysis of Three-Dimensional SDucts," Submitted to AIAA Joumal of Aircraft.

${ }^{18}$ Smith, C. F., Bruns, J. E., Harloff, G. J., and Debonis, J. R., "Three-Dimensional Compressible Turbulent Computations for a Diffusing S-Duct," Sverdrup Technology, Inc. NASA CR 4392, 1991.

${ }^{19}$ Vakili, A. D., Wu, J. M., Liver, P., and Bhat, M. K., "Experimental Investigation of Secondary Flows in a Diffusing S-Duct," The University of Tennessee Space Institute Tech. Rep. UTSI 86/14, 1984.

${ }^{20}$ Porro, A. R., Hingst, W. R., Wasserbauer, C. A., and Andrews, T. B., "The NASA Lewis Research Center Internal Fluid Mechanics Facility," NASA TM 105187, Sept. 1991.

${ }^{21}$ Wellborn, S. R., Reichert, B. A., and Okiishi, T. H., "Aerodynamic Measurement of the Subsonic Flow Through a Diffusing S-Duct," AIAA Paper 923201, 1992. Accepted for presentation at the 28th AIÃA/SAE/ASME Joint Propulsion Conference and Exhibit, July 6-8, Nashville, TN.

${ }^{22}$ Cooper, G. K., "The PARC Code: Theory and Usage," A.E.D.C. Tech. Rep. TR-87-24, Oct. 1987.

${ }^{23}$ Pulliam, T. H. and Steger, J. L., "Implicit FiniteDifference Simulations of Three-Dimensional Compressible Flow," AIAA Journal, Vol. 18, Oct. 1980, pp. 159167.

${ }^{24}$ Jameson, A., Schmidt, W., and Turkel, E., "Numerical Solutions of the Euler Equations by Finite Volume Methods Using Runge-Kutta Time-Stepping Schemes," AIAA Paper 81-1259, 1981.

${ }^{25}$ Pulliam, T. H., "Euler and Thin Layer Navier-Stokes Codes: ARC2D, ARC3D," The University of Tennessee Space Institute UTSI Publication E02-4005-023-84, Mar. 1984. Notes for Computational Fluid Dynamics User's Workshop.

${ }^{26}$ Baldwin, B. S. and Lomax, H., "Thin Layer Approximation and Algebraic Model for Separated Turbulent Flows," AIAA Paper 78-257, 1978.

${ }^{27}$ Speziale, C. G., Ridha, A., and Anderson, E. C., "A Critical Evaluation of Two-Equation Models for Near Wall Turbulence," ICASE Tech. Rep. 90-46, June 1990.

${ }^{28}$ Nichols, R. H., "A Two-Equation Model for Compressible Flows," AIAA Paper 90-0494, 1990.

${ }^{29}$ Schubauer, G. B. and Klebanoff, P. S., "Investigation of Separation of the Turbulent Boundary Layer," NACA TN 2133, 1950. 


\section{REPORT DOCUMENTATION PAGE}

Public reporting burden for this collection of information is estimated to average 1 hour per response, including the time for reviewing instructions, searching existing data sources, gathering and maintaining the data needed, and completing and reviewing the collection of information. Send comments regarding this burden estimate or any other aspect of this collection of information, including suggestions for reducing this burden, to Washington Headquarters Services, Directorate for information Operations and Aeports, 1215 Jefferson Davis Highway. Sutte 1204, Arlinglon, VA 22202-4302, and to the Office of Management and Budget, Paperwork Reduction Project (0704-01B8). Washington, DC 20503.
1. AGENCY USE ONLY (Leave blank)
2. REPOAT DATE
July 1992
3. REPORT TYPE AND DATES COVERED
Technical Memorandum

\section{TITLE AND SUBTITLE}

Navier-Stokes Analysis and Experimental Data Comparison of Compressible Flow in a Diffusing $S$-Duct

6. AUTHOR(S)

Gary J. Harloff, Bruce A. Reichert, and Steven R. Wcllborn

\section{PERFORMING ORGANIZATION NAME(S) AND ADDRESS(ES)}

National Aeronautics and Space Administration

Lewis Research Center

Cleveland, Ohio 44135-3191

9. SPONSORING/MONITORING AGENCY NAMES(S) AND ADDRESS(ES)

National Aeronautics and Space Administration

Washington, D.C. 20546-0001
5. FUNDING NUMBERS

WU-505-62-52
8. PERFORMING ORGANIZATION REPORT NUMBEA

E-7062

\section{SUPPLEMENTARY NOTES}

Prepared for the loth Applied Acrodynamics Conference sponsored by the American Institute of Aeronautics and Astronautics, Palo Alto,

California, June 22-24, 1992. Gary J. Harloff, Sverdrup Technology, Inc., Lewis Rescarch Center Group, Brook Park, Ohio 44142, Bruce A

Reichert, NASA Lewis Rescarch Center, Cleveland, Ohio. Steven R. Wellborn, Iowa State University, Ames, Iowa 500l0. Responsible person, Brucc A. Reichert, (216) 433-8397.

12a. DISTRIBUTION/AVAILABILITY STATEMENT

12b. DISTRIBUTION CODE

Unclassified - Unlimited

Subject Category 07

NASA TM-105683

AIAA-92-2699

3. ABSTAACT (Maximum 200 words)

Full three-dimensional Navier-Stokes computational results are compared with new experimental measurements for the flow field within a round diffusing $S$-duct. The present study extends previous computational and experimental results for a similar smaller scale S-duct. Predicted results are compared with the experimental static and total pressure fields, and velocity vectors. Additionally, wall pressures, velocity profiles in wall coordinates, and skin friction values are presented. The CFD results employ algebraic and $k-\varepsilon$ turbulence models. The CFD computed and experimentally determined separated flow field is carefully examined.

14. SUBJECT TERMS

15. NUMBER OF PAGES

Computational fluid dynamics; Inlet flow; Intake systems; Engine inlets

10

16. PRICE CODE

$\mathrm{A} 02$

\begin{tabular}{|c|c|}
\hline 17. SECURITY CLASSIFICATION \\
$\begin{array}{c}\text { OF REPORT } \\
\text { Unclassified }\end{array}$ & $\begin{array}{c}\text { 18. SECURITY CLASSIFICATION } \\
\text { OF THIS PAGE } \\
\text { Unclassified }\end{array}$ \\
\hline
\end{tabular}

NSN 7540-01-280-5500
19. SECURITY CLASSIFICATION OF ABSTRACT

Unclassified 